\title{
Emotion Expressiveness and Knowledge in Preschool-Age Children: Age-Related Changes
}

\author{
Nana Shin * \\ Ewha Womans University \\ Lisa Krzysik Brian E. Vaughn \\ Auburn University
}

\begin{abstract}
Emotion is a central feature of social interactions. In this study, we examined age-related changes in emotion expressiveness and emotion knowledge and how young children's emotion expressiveness and knowledge were related. A total of 300 children attending a daycare center contributed data for the study. Observation and interview data relevant to measures of emotion expressiveness and knowledge were collected and analyzed. Both emotion knowledge and expressed positive affect increased with age. Older preschool children expressed positive affect more frequently than did younger preschoolers. Older preschool children also labeled, recognized, and provided plausible causes mores accurately than did younger preschool children. In addition, we tested whether children's errors on the free labeling component conform to the structural model previously suggested by Bullock and Russell (1986) and found that preschool children were using systematic strategies for labeling emotion states. Relations between emotion expressiveness and emotion knowledge generally were not significant, suggesting that emotional competence is only gradually constructed by the child over the preschool years.
\end{abstract}

Keywords: emotion expressiveness, emotion knowledge, preschool-age children

There is a general consensus among developmental scientists concerning the centrality of emotion in the everyday lives of children (e.g., Campos, Thein, \& Owen, 2003; Cole, Martin, \& Dennis, 2004; Denham, 1998; Sroufe, 1996). Emotions serve, in part, to provide texture, color, and meaning to transactions between the child and her or his social and physical surround(s) (Barrett \& Campos, 1987; Holodynski \& Friedlmeier, 2006; Lazarus, 1999; Sroufe, 1996), and both peers and adult caregivers often interpret the

* Corresponding Author: Nana Shin, Assistant Professor, Department of Child Development, Ewha Womans University, 402-1 Ecology Building, Seoul, 120-750, South Korea. E-mail: nanashin@ewha.ac.kr child's expressions of affect as communicative signals reflecting the child's present internal state(s) (e.g., Ainsworth, Blehar, Waters, \&Wall, 1978; Denham et al., 2001; Fogel, Nelson-Goens, \& Hsu, 2000; Tronick, 1989). With the advances in cognitive and language capacity that take place after infancy/toddlerhood, children begin to acquire verbal labels for emotions (e.g., Denham, Caverly et al., 2002; Russell \& Widen, 2002; Widen \& Russell, 2003, 2004) and an understanding of the circumstances that give rise to affect experiences in the self and others (e.g., Denham, 1998; Saarni, 1999). These expressive/communicative and cognitive (i.e., knowledge structure relevant to the display and 
interpretation of affect and emotion) skills have been considered as important aspects of emotional competence. In this study, we assessed two facets of emotional competence (i.e., observed expressions of positive and negative affect and emotion knowledge from child interviews) in terms of age-related changes (younger vs. older preschool children) and the relations between two emotional competence facets. Our data afford possibilities for replicating previously reported findings regarding the acquisition of emotion labels and causes of emotion states (e.g., Denham, 1998; Widen \& Russell, 2003, 2004)

\section{Age-Related Changes in Emotion Expressiveness and Knowledge}

Emotional competence consists of several skills, or facets, that connect emotions to behavior (e.g., physical expression of emotion) and cognition (e.g., recognizing and labeling emotions), and the adapted organization among these facets is characterized as emotional competence (Denham et al., 2002). Developmental studies of expressed emotion have usually been framed around questions concerning the ages at which facial/ vocal/gestural expressions of discrete emotions are seen in the repertoires of infants or young children. Early studies (e.g., Field \& Walden, 1982; Malatesta, Culver, Tesman, \& Shepard, 1989; Oster, 1978; Oster \& Ekman, 1978) showed that adult-like expressions of basic emotions (i.e., affect states shared with other species) were present in the repertoires of infants and children and that differences among expressions of basic emotions could be discriminated (if not understood) during the first year of life (see Izard \& Malatesta, 1987 and Walker-Andrews, 1997 for reviews). During the preschool years, most children begin to experience and express more sophisticated emotions such as guilt and embarrassment, although findings regarding age-related differences in aspects of expression were inconsistent (e.g., Holodynski, 2004; Malatesta et al., 1989).
In addition, most investigators agree that infants/toddlers exhibit these expressions in appropriate (i.e., when adult observers think that a given discrete emotion would reflect the meaning of some infant-environment transaction) contexts by the age of 18- to 22months, if not before (e.g., Ackerman, Abe, \& Izard, 1998; Malatesta et al., 1989; Oster \& Ekman, 1978), although a given "context" may not elicit a specific emotional response each time it is encountered and may elicit different emotional responses from different children (Sroufe, 1996). However, children generally begin using emotion-relevant words in conversations (at least with adults) by the third year of life (i.e., 24 - 36 months, Bloom, 1998) and by the fourth year, children can label some emotion states in response to adult questions (e.g., "how does this child feel?" asked as the child views a schematic or photographic representation of a face displaying an emotion expression) and can correctly recognize some emotion displays when prompted (e.g., "show me the sad face," see Denham, 1998). Thus, the child's experience of discrete affects has a rather long history prior to the time at which he or she can articulate that experience using the emotional lexicon familiar to adults.

Accuracy in labeling and recognizing increases with age for basic emotion categories (see Ekman, 1999, for a discussion of basic emotions and Brown \& Dunn, 1996; Denham, 1998, for reports of age-increases in emotion knowledge) and several studies (e.g., Widen \& Russell, 2008) have suggested knowledge about specific emotion states is acquired systematically (rather than in a random order), with "happy" (or near equivalent) being the first label used appropriately, followed by "anger" (mad) or "sad" (with the order of acquisition varying across children). Knowledge about expressions of fear (scared), disgust, and surprise tend to be acquired after knowledge about the previously identified emotion states (e.g., Bullock \& Russell, 1986; Denham, 1998; Russell \& Widen, 2002). By five years-of-age, most children can provide plausible causes of emotions in others such as knowing what types of situations elicit different 
affect states (Denham and Zoller, 1991; Widen \& Russell, 2004). These patterns of results suggest that the preschool period (nominally 36to 66-months-of-age) is a time of rapid acquisition of knowledge about emotion and our data allowed us to test if the external correlates of emotion knowledge would show age-related shifts as children acquire more sophisticated, understanding(s) of discrete affect expressions.

Russell and associates (e.g., Bullock \& Russell, 1986; Widen \& Russell, 2003, 2008) have studied children's errors in labeling emotions to test the hypothesis that their emotion categories would be initially broadly based on the dimensions of pleasure and arousal and would narrow with development. They reported that children's errors were more likely from emotion categories that were similar in levels of pleasure and arousal, suggesting that such errors should be considered as an important aspect of the development of emotion knowledge. In this study, we examined how well children recognize, label, and suggest causes of each emotion category and whether their errors followed a systematic pattern.

\section{Emotion Expressiveness and Knowledge in Preschool-aged Children}

Several studies have used quantitative indices of expressivity in relation to preschoolers' emotion knowledge but results have not been especially consistent. For example, although Denham et al. (2003) reported that the proportion of observed positive (happy) and negative (sad) affects showed modest but significant relations with scores for emotion knowledge, Miller, Fine, Gouley, Seifer, Dickstein, and Shields (2006) found that only positive affective expressivity was associated with emotion knowledge, and Arsenio, Cooperman, and Lover (2000) did not find any significant associations between measures of emotion knowledge and either positive or negative expressivity. These mixed findings may be partly due to the fact that emotion expression and emotion knowledge develop at different rates and also partly due to differences in sample sizes across studies (i.e., such that a modest association in one study might reach significance but fail to reach significance in a study with a smaller sample). In this study, we examined relations among three facets of emotional knowledge (i.e., labeling, recognition, stating plausible causes of emotions) and their relations with affect expressivity to add more insight on this issue.

\section{The Present Study}

Data for this report came from an ongoing program of research concerning the normative and individual difference implications of emotional and social competence in preschool children. Expressed positive and negative affect was obtained from direct classroom observation. Emotion knowledge tasks included free labeling of posed expressions, identifying a posed emotional expression after being provided a label, and stating plausible causes of a given emotion. Our first goal was to examine agerelated changes in emotion expressiveness for younger $v s$. older preschool aged children. Based on results reported by Akers (2006), we hypothesized that older preschool children would be more positively expressive and less negatively expressive than younger children. We also investigated how well younger vs. older children would label, recognize, and provide plausible causes of emotion states. Children's errors in the free labeling task were also examined to test whether they would be random or conform to the structural model suggested by Russell and associates (e.g., Bullock \& Russell, 1986; Widen \& Russell, 2003). We expected that older preschool children would have better knowledge of discrete emotions and make fewer unlikely errors than younger children. Our second goal was to assess relations between the two facets of emotional competence (i.e., emotion expressiveness and knowledge) to address questions concerning the extent to which emotional competence can be considered a coherent construct that unifies expression and knowledge. We expected that children expressing positive emotion more frequently 
Shin, Krzysik, \& Vaughn

(and/or negative affect less frequently) would be more knowledgeable about emotions.

\section{Methods}

\section{Participants}

A total of 300 children (134 girls, 166 boys) attending a daycare center managed by a major southeastern university contributed data for the study. Classes were constituted at the beginning of the academic year based on the ages of the children. Those between 36 and 48 months of age were grouped together and children between 48 and 60 months were grouped together at the beginning of the academic year. However, because data collection spanned the full academic year, many children had a birthday before being observed. To avoid confusion, we refer to the groups as "younger" and "older" rather than assigning an age to them. 161 children ( 75 girls, 86 boys) were in classrooms of younger children and 139 (59 girls, 80 boys) were in classrooms of older children.

The daycare facility from which participants were recruited is accredited by the National Association for the Education of Young Children and enrolls children from different ethnic groups reflecting the population in the community it serves. The majority of families are middle class (by the standards of the larger metropolitan community) and many parents are professionals (e.g., attorneys, dentists, accountants, business executives). Family income estimates for the center are not available, however, in a previous study that included $\sim 20 \%$ of children in this sample, the median annual family income range was between $\$ 75 \mathrm{~K}$ and $\$ 100 \mathrm{~K}$ and $40 \%$ of families reported annual family incomes above $\$ 100 \mathrm{~K}$. Less than $5 \%$ of families reported incomes under $\$ 25 \mathrm{~K}$. Approximately $35 \%$ of the children served $(33.5 \%$ of present sample) are from ethnic minority families (predominantly African-American) and job titles for parents of minority children did not differ appreciably from those of majority families. Parents were informed about the project by classroom- teachers or the center director and they signed informed consent forms agreeing to their child's participation in the study. Consent rates ranged from 90 to $100 \%$ across all classrooms and children assented to all interview and interaction tasks before they left the classroom to complete these tasks.

\section{Procedures}

All assessments took place in the daycare center. Children's emotion expressions were observed during the natural classroom activities. Children were observed across all available settings (e.g., free-play and group activities in the classroom, meals, playground, transitions between activities. To assess emotion knowledge, a research assistant interviewed each child individually in a quiet area outside the classroom.

\section{Measures}

Emotion expressiveness. Two observers collected emotion expressiveness data. Observers did not work in pairs and rarely observed a given child simultaneously. Working from class rosters, these observers watched a target child for each observation round when the child's name appeared on the list. All children present in the classroom during a given round of observation were observed before any child was watched twice. Approximately 200 rounds of observations (100 for each observer) were collected in each classroom.

For emotion expressiveness observations, an observer watched a given child for a 6-sec. interval and recorded children's affect expressiveness. Children's affect expressions were categorized as positive, negative or neutral. Both positive and negative expression could be coded in a single 6-sec. interval if the child expressed both affects during the interval. A total of 218 children were observed for classroom affect expressions. The total number of positive and negative emotions was calculated, divided by the number of observation rounds for which the target child was actually present in the 
classroom to adjust for absences from the classroom during observations and for differences in the number of observational rounds across classroom.

Emotion knowledge. Children's knowledge about their emotions was assessed through a modified version of Denham's emotion knowledge tasks (e.g., Denham \& Couchoud, 1990). The interviewer spent some time playing with the child to build a rapport. The interviewer then showed the child photographs of prototypical facial expressions of five "basic" emotions states (happy, sad, anger, fear, surprise) plus two other emotions (embarrassment, guilt). Children were first asked to label pictures of facial expressions (e.g., "how does this child feel?" labeling), then to identify each expression depicted in the pictures (e.g., "where is the happy face?" recognition), and finally to suggest events that would make the child to feel that way (plausible cause). The order of presentation for the emotion stimuli was random, and all seven faces were present for the recognition task. The assessment took 15-20 minutes per child. 300 children completed the emotion knowledge interview. Their responses were scored 0 if incorrect and 1 if correct. Scores were summed across seven emotion states to create total emotion labeling, total emotion recognition, and total emotion cause scores.

\section{Results}

Results are presented in three sections. First, as preliminary analyses, comparisons of means across age and gender were evaluated to detect potential main and interaction effects among the variables. Because each variable has cases with missing data, univariate ANOVAs were calculated instead of MANOVAs. Second, we evaluated the proportion of correct responses for each emotion category in three areas of emotion knowledge (children's abilities to recognize discrete emotion expressions without prompts, identify these expressions with prompts, and suggest a plausible cause of the emotion). We also tested whether children's errors on the free labeling component conform to the structural model previously found for forced-choice (Bullock \& Russell, 1986) and free-choice (Widen \& Russell, 2003, 2008) labeling tasks. In the last section, we examined zero-order correlations between the emotional expression and emotion knowledge variable sets.

\section{Age and Sex Differences}

Univariate ANOVAs tested effects of age and sex as well as their interactions on scores for emotion expressiveness and knowledge variables. No interaction effects of age and sex were significant, but main effects of both age and sex were found for the emotion knowledge variables. There were significant main effects for age on emotion recognition, $F(1,296)=24.40, p$ $<.001$,emotion labeling, $F(1,296)=23.35, p$ $<.001$, and emotion causes, $F(1,296)=33.13, p$ $<$.001. In each instance, older children performed better than younger children. Significant main effects of age were also found for both expressed affect scores, $F(1,214)=5.12$, $p<.05$, for rate scores of positive expression, and $, F(1,214)=7.79, p<.01$, for rate scores of negative expression. Older preschoolers expressed positive affects at higher rates and younger children expressed negative affects more frequently than older preschoolers. Significant main effects of sex were also found for both children's abilities to label emotions, $F(1,296)=5.24, p<.05$, and to suggest appropriate causes of emotion states, $F(1,296)$ $=5.40, p<.05$. Girls performed better than boys. Means, standard deviations, and $F$-values for significant univariate effects are presented in Table 1. Based on these findings, subsequent analyses were conducted separately for older and younger children. Because of significant sex effects on two emotion knowledge variables (i.e., labeling and stating causes of emotion states), we residualized each variable on sex and used these residualized scores in subsequent analyses. 
Shin, Krzysik, \& Vaughn

Table 1

Means, Standard Deviations, and Univariate ANOVA Results for Age and Sex Analyses

\begin{tabular}{|c|c|c|c|c|}
\hline Variable & Effect & Means & $S D s$ & F-value \\
\hline \multicolumn{5}{|l|}{ Emotion Knowledge } \\
\hline Emotion recognition & Young vs. Old & 3.28 vs. 4.15 & .12 vs. .13 & $24.40^{* * *}$ \\
\hline \multirow[t]{2}{*}{ Emotion labeling } & Young vs. Old & 2.89 vs. 3.58 & .10 vs. .11 & $23.35^{* * *}$ \\
\hline & Boys vs. Girls & 3.07 vs. 3.40 & .10 vs. .11 & $5.24^{*}$ \\
\hline \multirow[t]{2}{*}{ Emotion causes } & Young vs. Old & 3.71 vs. 4.69 & .12 vs. .13 & $33.13^{* * *}$ \\
\hline & Boys vs. Girls & 4.00 vs. 4.40 & .11 vs. .13 & $5.40^{*}$ \\
\hline \multicolumn{5}{|l|}{ Emotion Expressiveness } \\
\hline Positive affect & Young vs. Old & .16 vs. .18 & .01 vs. .01 & $5.12^{*}$ \\
\hline Negative affect & Young vs. Old & .04 vs. .00 & $.00 \mathrm{vs} . .00$ & $7.79^{* *}$ \\
\hline
\end{tabular}

Table 2

Proportion Correct on Each Emotion

\begin{tabular}{cccccccccc}
\hline \multirow{2}{*}{$\begin{array}{c}\text { Types of } \\
\text { Emotions }\end{array}$} & \multicolumn{3}{c}{ Labeling } & \multicolumn{3}{c}{ Recognition } \\
\cline { 2 - 10 } & Older & Younger & $\mathrm{Z}$ & Older & Younger & $\mathrm{Z}$ & Older & Younger & $\mathrm{Z}$ \\
\hline Happy & .93 & .86 & 1.95 & .72 & .53 & $3.40^{* * *}$ & .86 & .85 & 0.39 \\
Sad & .81 & .63 & $3.40^{* * *}$ & .53 & .35 & $3.11^{* *}$ & .88 & .73 & $3.42^{* * *}$ \\
Anger & .81 & .61 & $3.71^{* * *}$ & .91 & .76 & $3.39^{* * *}$ & .82 & .63 & $3.70^{* * *}$ \\
Fear & .50 & .40 & 1.84 & .68 & .57 & $2.00^{*}$ & .93 & .78 & $3.64^{* * *}$ \\
Surprise & .52 & .36 & $2.75^{* *}$ & .81 & .65 & $2.97^{* *}$ & .79 & .56 & $4.26^{* * *}$ \\
\hline
\end{tabular}

${ }^{*} p<.05 .{ }^{* *} p<.01 .{ }^{* * *} p<.001$.

\section{Proportion Correct on Each Emotion Category}

Proportion correct for each emotion is presented in Table 2. When asked to identify posed photographs of discrete emotions (e.g., "show me the happy face"), children were most accurate at recognizing anger and least accurate at recognizing sadness. In the free labeling task (i.e., "how does this child feel?"), children were most successful at labeling happiness and least successful at labeling fear for older children and surprise for younger children. Children's performances in terms of providing plausible causes of the emotions were best for fear for older children and happiness for younger children and worst for surprise for both older and younger children. In all three tasks, proportions of correct responses for older children were significantly higher than for younger children. Only three proportion scores (i.e., happiness and fear labeling, happiness cause) were not significantly different for older and younger children. Despite these significant mean differences, the general pattern in success rate was the same for older and younger children.

\section{Testing Bullock and Russell's Structural Model (1986)}

To test whether children's errors in the free labeling task conform to the structural model 
suggested by Bullock and Russell (1986) and Widen and Russell (2003, 2008), we replicated methods used by Widen and Russell's (2003, 2008). Prior to counting the number of times children made correct responses and errors for the five target emotion categories (i.e., happiness, sadness, anger, fear, and surprise), a structural model was constructed (see Table 3). In this model, the emotion categories were rank ordered, with similar emotions (e.g., happy and surprise) placed next to each other and opposing emotions (e.g., happy and sad) were positioned furthest apart. Children's responses to guilt and embarrassment were not included in the model because most children failed to provide correct labels for these emotion states. Table 3 shows the number of times each label was applied to each facial expression for older and younger children. The top portion of each column is the facial expression shown to the children. Children's responses to these facial expressions are displayed in the left column as row headings. When children provided emotion labels other than 5 target emotion categories, those responses were categorized as "others." All correct responses are on the diagonal and all the errors are above and below the diagonal. Children's incorrect responses were classified into four steps, derived from the model proposed by Bullock and Russell (1986), with higher step indicating more unlikely errors. Step 1 errors were those for the most adjacent emotion categories (e.g., calling the happy face surprised). These scores are located immediately below and above the diagonal (the subdiagonal and superdiagonal). Children's responses that were incorrect by two steps were placed below the subdiagonal and above the superdiagonal (Step 2). Step 3 errors were positioned below and above the Step 2 errors. Finally, Step 4 errors were based on children's incorrect responses for the furthest positioned emotion categories (e.g., calling the "happy" face "sad").

The cells off each diagonal were summed and divided by the number of cells in that diagonal to calculate the relative frequency of correct answers and errors. For example, the relative frequency of correct answers for older children was calculated with scores that were on the diagonal (e.g., $[129+72+71+111+112=$ $495] / 5=99.00)$. Further, Step 1 through Step 4 scores were calculated based on children' incorrect responses. Table 3 shows that for both older and younger children, the relative frequency scores decrease from Step 1 to Step 4, although there was a slight reversal between Step 3 and Step 4. Children were more likely mislabel a face with a label from a similar emotion category than from a dissimilar one, suggesting that their emotion knowledge errors conformed to the structural model. We return to this point in the discussion.

Based on these results, we constructed error scores for each emotion category. Error scores were assigned based on their distances from the target emotion (e.g., for the happy face, 1= happy, $2=$ surprised, $3=$ scared, $4=$ angry, and $5=s a d$ ). Correlations among error scores for each emotion category revealed that children's errors for the happy emotion were not significantly related to error scores for other emotion categories because majority of children provided correct answers for the happy face. Thus, total error scores were calculated by summing error scores across four emotion categories (i.e., sad, angry, scared, and surprised). There was no sex difference in total error scores.

\section{Correlations between Emotion Expressiveness and Knowledge}

Within-age (older vs. younger children) correlations between emotion expressiveness and knowledge are presented in Table 4. As expected, three aspects of emotion knowledge were significantly related to each other at both age levels. Correlations ranged from .23 to .50 , and all correlations were significant at the level of $\alpha$ $=.01$. Children's error scores from the free labeling task were significantly and negatively related to all three aspects of emotion knowledge variables for both older and younger children. Correlations between emotion knowledge and affect expression variables were also calculated. A significant relation was only found for older children. Children with higher scores for 
Shin, Krzysik, \& Vaughn

Table 3

Structural Models of Errors of Free Labeling

\begin{tabular}{|c|c|c|c|c|c|c|c|}
\hline Response & & & Face & & & & \\
\hline Older & Happy & Surprised & Fear & Angry & Sad & Total & \\
\hline Happy & $129^{\mathrm{a}}$ & $45^{b}$ & $13^{c}$ & $0^{\mathrm{d}}$ & $1^{\mathrm{e}}$ & 125 & ${ }^{\mathrm{a}}$ Correct $495 / 5=99.00$ \\
\hline Surprised & $0^{\mathrm{b}}$ & $72^{\mathrm{a}}$ & $12^{\mathrm{b}}$ & $0^{\mathrm{c}}$ & $1^{\mathrm{d}}$ & 64 & ${ }^{\mathrm{b}}$ Step $168 / 8=12.13$ \\
\hline Fear & $0^{\mathrm{c}}$ & $3^{\mathrm{b}}$ & $71^{\mathrm{a}}$ & $0^{\mathrm{b}}$ & $0^{\mathrm{c}}$ & 50 & ${ }^{\mathrm{c}}$ Step $230 / 6=5.00$ \\
\hline Angry & $0^{\mathrm{d}}$ & $0^{\mathrm{c}}$ & $3^{\mathrm{b}}$ & $111^{\mathrm{a}}$ & $16^{\mathrm{b}}$ & 92 & ${ }^{\mathrm{d}}$ Step $31 / 4=.25$ \\
\hline Sad & $1^{\mathrm{e}}$ & $0^{\mathrm{d}}$ & $17^{\mathrm{c}}$ & $18^{\mathrm{b}}$ & $112^{\mathrm{a}}$ & 93 & ${ }^{\mathrm{e}}$ Step $42 / 2=1.00$ \\
\hline Others & 10 & 19 & 23 & 10 & 9 & 51 & \\
\hline Total & 139 & 139 & 139 & 139 & 139 & & \\
\hline Younger & Happy & Surprised & Fear & Angry & Sad & & \\
\hline Happy & $137^{\mathrm{a}}$ & $79^{b}$ & $32^{\mathrm{c}}$ & $4^{d}$ & $13^{\mathrm{e}}$ & 242 & ${ }^{\mathrm{a}}$ Correct $458 / 5=91.60$ \\
\hline Surprised & $4^{\mathrm{b}}$ & $58^{\mathrm{a}}$ & $4^{b}$ & $0^{\mathrm{c}}$ & $2^{d}$ & 60 & ${ }^{\mathrm{b}}$ Step $1157 / 8=19.63$ \\
\hline Fear & $1^{\mathrm{c}}$ & $2^{\mathrm{b}}$ & $64^{\mathrm{a}}$ & $1^{\mathrm{b}}$ & $4^{\mathrm{c}}$ & 58 & ${ }^{\mathrm{c}}$ Step $272 / 6=12.00$ \\
\hline Angry & $1^{\mathrm{d}}$ & $1^{\mathrm{c}}$ & $11^{\mathrm{b}}$ & $98^{\mathrm{a}}$ & $24^{\mathrm{b}}$ & 114 & ${ }^{\mathrm{d}}$ Step $310 / 4=2.50$ \\
\hline Sad & $2^{\mathrm{e}}$ & $3^{d}$ & $34^{\mathrm{c}}$ & $32^{\mathrm{b}}$ & $101^{\mathrm{a}}$ & 126 & ${ }^{\mathrm{e}}$ Step $415 / 2=7.50$ \\
\hline Others & 16 & 18 & 16 & 26 & 29 & 65 & \\
\hline Total & 161 & 161 & 161 & 161 & 161 & & \\
\hline
\end{tabular}

Table 4

Correlations between Emotion Expressiveness and Emotion Knowledge

\begin{tabular}{lcccccc}
\hline & 1 & 2 & 3 & 4 & 5 & 6 \\
\hline Emotion Expressiveness & & & & & & \\
$\quad$ 1. Positive affect & - & $.29^{* *}$ & .07 & -.06 & .18 & -.12 \\
$\quad$ 2. Negative affect & $.18^{*}$ & - & .03 & $-.25^{*}$ & .07 & .01 \\
Emotion Knowledge & & & & & & \\
$\quad$ 3. Labeling & .02 & -.04 & - & $.49^{* * *}$ & $.36^{* * *}$ & $-.85^{* * *}$ \\
4. Recognition & -.13 & -.05 & $.50^{* * *}$ & - & $.23^{* *}$ & $-.54^{* * *}$ \\
5. Causes & -.16 & -.18 & $.50^{* * *}$ & $.45^{* * *}$ & - & $.39^{* * *}$ \\
6. Free-labeling errors & .16 & .14 & $-.84^{* * *}$ & $-.42^{* * *}$ & $-.44^{* * *}$ & - \\
\hline
\end{tabular}

Note: Scores for younger children are below the diagonal and scores for older children are above the diagonal. ${ }^{*} p<.05 .{ }^{* *} p<.01 .{ }^{* * *} p<.001$.

emotion recognition expressed negative affects less frequently in the classroom. These findings suggest that in general, emotion expressiveness and knowledge were independent measures of emotional competence for these children.

\section{Discussion}

We had two broad goals in this study. First, our data allowed us to examine age-related changes in emotion expressiveness for younger 
$v s$. older preschool age children and emotion knowledge based on individual interviews. Prior research findings (e.g., Akers, 2006; Denham, 1998) suggested that older preschool children would be more positively expressive and less negatively expressive than younger children, and would demonstrate greater understanding of discrete emotions. We also expected to find that children would acquire emotion knowledge systematically (e.g., Widen \& Russell, 2003, 2008), rather than in a haphazard or random manner.

With regard to the first goal, all expectations were met. Older preschool children expressed positive affect more frequently and younger children expressed negative affect more frequently in the classroom. Older preschool children also labeled, recognized, and rationalized discrete emotion states more accurately than did younger preschool children. Perhaps more interestingly, an examination of their error patterns suggested that these preschool children were using systematic strategies for labeling emotion states that they had not already mastered. The children were most accurate at labeling happiness and least accurate at labeling fear and surprise when asked to name the emotion posed in a photograph without a prompt. These findings are consistent with results reported by Widen and Russell (2003) who suggested that the acquisition of emotion labels follows a systematic order (i.e., happy, angry, and sad emerged earlier than did surprise and fear). However, when the interviewer provided an emotion label, children were most successful in identifying anger and least successful when identifying sadness. These findings are somewhat inconsistent with previous studies, which have reported that children recognize happiness and sadness more accurately than anger, fear, and surprise (Camras \& Allison, 1985; Walden \& Field, 1982). Further, and contrary to some studies examining emotion recognition (Bullock \& Russell, 1986; Smith \& Walden, 1998), these children did not have much difficulty in identifying facial expressions of surprise. Finally, when asked to suggest the causes of each facial expression, the children readily provided plausible causes for happiness and were least able to provide plausible causes for surprise. Even though older and younger children differed in their performance (i.e., older children were more successful across the board), the general patterns of errors were the same for both age-levels.

It is not clear why children in this study had difficulty recognizing sadness in the posed photograph or why they were successful at identifying the posed surprised expression. However, when asked to choose a sad face, many children chose the posed embarrassed or guilty faces, which shared some features in common with the posed sad facial expression (e.g., closed mouth, gaze down, furrowed eyebrow). These results support the argument that young children's emotion categories are relatively broad, based on the dimensions of hedonic tone and arousal, and as they grow older, they narrow their emotion categories in a systematic manner (Bormann-Kischkel, Hildebrand-Pascher, \& Stegbauer, 1990; Bullock \& Russell, 1984, 1985, 1986; Hosie, Gray, Russell, Scott, \& Hunter, 1998; Widen \& Russell, 2003).

In addition to examining children's ability to recognize, label, and suggest causes of each emotion state, we also tested whether children's free labeling responses conformed to Bullock and Russell's (1986) structural model constructed from data obtained during a forcedchoice labeling task. Widen and Russell (2003, 2008) tested this model with a free-labeling task and found that children's errors were more likely from emotion categories adjacent to the target category (surprised for 'happy', rather than sad for 'happy'). We replicated Widen and Russell's findings, and thus supported Bullock and Russell's (1986) model even though there was a reversal between Step 3 and Step 4 (i.e., more errors at a greater conceptual distance). The difference between Step 3 and Step 4 was very small for older children. But for younger children, this difference was larger and mostly due to the failure to correctly label sad facial expressions. These findings suggest that when young children make errors in identifying the 
faces of emotion, these errors reflect a systematic attempt at mapping unmastered emotion labels to currently understood labels on the basis of shared features (in this case, muscle contractions leading to differing facial configurations and associated understandings of hedonic tone).

Second, our data allowed us to examine the dimensionality of the "Emotional Competence" construct in the younger and older preschool groups. If emotional competence is, in fact, an organizing construct that unifies expression, understanding, and regulation of affect and emotion, we might expect that measures of these several facets of emotional competence should covary to a significant degree. However, if emotional competence is simply a categorical container for collecting different themes found in emotional development research, then there is no a priori expectation that the dimensions should be significantly associated. We were able to examine this explicitly for the expressive and knowledge aspects of emotional competence.

Results for construct coherence were not very clear. Emotion knowledge variables showed significant inter-correlations at both age levels, suggesting that understandings about discrete emotions are acquired together (i.e., when the child can name the emotion state in response to the presentation of a posed expression, she or he can also discriminate that emotion and provide a plausible reason why the emotion might be elicited for the child posing the expression). However, neither do our correlation results relating expression and knowledge variables suggest that emotional competence is a coherent construct for preschool age children. Among the younger children, no cross-facet associations were significant and only one correlation between emotion recognition and expressed negative affect was significant for the older group. Thus, we are inclined to treat this association as a chance event, rather than as a substantive finding for this study. These findings suggest that emotional competence is only gradually constructed by the child over the preschool years. For preschool age children, there remain many questions to explore regarding the organization of the emotional competence construct at different age periods, the socialization and intra-individual antecedents of individual differences regarding each facet of emotional competence, and outcomes contingent on the attainment of emotional competence in the school-age years. We view this study as a contribution to the initiation of a research program to further develop and explore these questions.

Taken together, the results of our analyses are at least partially consistent with the existing literature on the development of emotional competence. Individual differences in emotional expressiveness and emotion knowledge are evident in the $4^{\text {th }}$ year of life (i.e., between 36 and 48 months), however, the two facets of emotional competence are only modestly related at both age levels studied. These results suggest that emotional competence is an emergent construct that is only beginning to be evident in the $4^{\text {th }}$ year, but becomes increasingly coherent and implicative with age. Age-related differences, favoring older children were observed for the expression and knowledge variables and both the order of acquisition of emotion labels and the systematic errors in labeling were consistent, for the most part, with previous research (e.g., Widen \& Russell, 2003, 2008). In future research, it will be useful to examine this agechange in patterns of relations with a sample studied longitudinally.

Acknowledgements: The research reported here has been supported in part by NSF grants BCS 0126163, BCS 0623019, BCS 0843919, BCS 1251322, and NIFA Hatch Project \#ALA042-1-09042. This work was supported by the National Research Foundation of Korea Grant funded by the Korean Government (NRF-2013S1A3A2055259).

\section{References}

Ackerman, B. P., Abe, J. A., \& Izard, C. (1998). Differential emotions theory and emotional development: Mindful of modularity. In. M. F. Mascolo \& S. Griffin (Eds.), What develops in 
emotional development (pp.85-106). New York: Plenum.

Akers, C. V. (2006). The expression of affect as correlate and predictor of social competence for preschool children. Unpublished M. S. thesis, Department of Human Development and Family Studies, Auburn University, USA.

Ainsworth, M. D. S., Blehar, M. C., Waters, E., \& Wall, S. (1978). Patterns of attachment: Psychological study of the strange situation. Hillsdale, NJ: Erlbaum.

Arsenio, W. F., Cooperman, S., \& Lover, A. (2000). Affective predictors of preschooler's aggression and peer acceptance: Direct and indirect effects. Developmental Psychology, 36, 438-448.

Barrett, K., \& Campos, J. (1987). Perspectives on emotional development II: A functionalist approach to emotions. In J. Osofsky (Ed.), Handbook of infant development (2nd ed., pp. 555-578). New York: Wiley.

Bloom, L. (1998). Language acquisition in its developmental context. In D. Kuhn \& R. S. Seigler (Eds.), Handbook of child psychology: Vol. 2. Cognition, perception, and language ( $5^{\text {th }}$ ed., pp. 309-370). New York: Wiley.

Bormann-Kischkel, C., Hildebrand-Pascher, S., \& Stegbauer, G. (1990). The development of emotional concepts: A replication with a German sample. International Journal of Behavioral Development, 13, 355-372.

Brown, J. R., \& Dunn, J. (1996). Continuities in emotion understanding from three to six years. Child Development, 67, 789-802.

Bullock, M., \& Russell, J. A. (1984). Preschool children's interpretation of facial expressions of emotion. International Journal of Behavioral Development, 7, 193-214.

Bullock, M., \& Russell, J. A. (1985). Further evidence on preschoolers' interpretations of facial expressions of emotion. International Journal of Behavioral Development, 8, 15-38.

Bullock, M., \& Russell, J. A. (1986). Concepts of emotion in developmental psychology. In C. E. Izard \& P. B. Read (Eds.), Measuring emotions in infants and children (Vol. 2, pp.203-237). Cambridge, England: Cambridge University Press.
Campos, J. C., Thein, S., \& Owen, D. (2003). Emotional expressions as behavioral regulators. Annals of the New York Academy of Science, 1000, 110-134.

Camras, L. A., \& Allison, K. (1985). Children's understanding of emotional facial expressions and verbal labels. Journal of Nonverbal Behavior, 9, 84-94.

Cole, P. M., Martin, S. E., \& Dennis, T. A. (2004). Emotion regulation as a scientific construct: Methodological challenges and directions for child development research. Child Development, 75, 317-333.

Denham, S. A. (1998). Emotional development in young children. New York: Guilford.

Denham, S. A., Blair, K., DeMulder, E., Levitas, J., Sawyer, K., Auerbach-Major, S., \& Queenan, P. (2003). Preschool emotional competence: Pathway to social competence? Child Development, 74, 238-256.

Denham, S. A., Blair, K., Schmidt, M., \& DeMulder, E. (2002). Compromised emotional competence: Seeds of violence sown early? American Journal of Orthopsychiatry, 72, 70-82.

Denham, S. A., Caverly, S., Schmidt, M. Blair, K., DeMulder, E., Caal, S., Hamada, H., \& Mason, T. (2002). Preschoolers' understanding of emotions: Contributions to classroom anger and aggression. Journal of Child Psychology and Psychiatry, 43, 901916.

Denham, S. A., \& Couchoud, E. A. (1990). Young preschoolers' understanding of emotions. Child Study Journal, 20, 171-192.

Denham, S. A., Mason, T., Caverly, S., Schmidt, M., Hackney, R., Caswell, C., \& DeMulder, E. (2001). Preschoolers at play: Co-socialisers of emotional and social competence. International Journal of Behavioral Development, 25, 290-301.

Denham, S. A., \& Zoller, D. (1991). "When my hamster died, I cried": Preschooler's attributions of the causes of emotions. Journal of Genetic Psychology, 152, 371-373.

Ekman, P. (1999). Basic emotions. In T. Dalgleish and M. Power (Eds.), Handbook of cognition and emotion (pp. 45-60). Sussex, 
U.K.: John Wiley \& Sons, Ltd.

Field, T. M., \& Walden, T. A. (1982). Production and discrimination of facial expressions by preschool children. Child Development, 53, 1299-1311.

Fogel, A., Nelson-Goens, G. C., \& Hsu, H-C. (2000). Do different infant smiles reflect different positive emotions? Social Development, 9, 497-520.

Hoise, J. A., Gray, C. D., Russell, P. A., Scott, C., \& Hunter, N. (1998). The matching of facial expressions by deaf and hearing children and their production and comprehension of emotion labels. Motivation and Emotion, 22, 293-313.

Holodynski, M. (2004). The miniaturization of expression in the development of emotional self-regulation. Developmental Psychology, 40, 16-28.

Holodynski, M., \& Friedlmeier, W. (2006). Development of emotions and emotion regulation. New York: Springer.

Izard, C. E., \& Malatesta. C. Z. (1987). Perspectives on emotional development I: Differentialemotions theory of early emotional development. In. J. D. Osofsky (Ed.), Handbook of infant development $\left(2^{\text {nd }}\right.$ ed., $\mathrm{pp}$. 494-554). New York: Wiley.

Lazarus, R. S. (1999). Stress and emotion. New York: Springer.

Malatesta, C. Z., Culver, C., Tesman, J. R., \& Shepard, B. (1989). The development of emotion expression in the first two years of life. Monographs of the Society for Research in Child Development, 54, 1-104.

Miller, A. L., Fine, S. E., Gouley, K. K., Seifer, R., Dickstein, S., \& Shields, A. (2006). Showing and telling about emotions: Interrelations between facets of emotional competence and associations with classroom adjustment in Head Start preschoolers. Cognition and Emotion, 20, 1170-1192.

Oster, H. (1978). Facial expression and affect development. In M. Lewis, \& L. Rosenblum (Eds.), The development of affect (pp. 43-75). New York: Plenum.
Oster, H., \& Ekman, P. (1978). Facial behavior in child development. Minnesota Symposia on Child Psychology, 11, 231-276.

Russell, J. A., \& Widen, S. C. (2002). Words versus faces in evoking children's knowledge of the causes of emotions. International Journal of Behavioral Development, 26, 97103.

Saarni, C. (1999). The development of emotional competence. New York: Guilford.

Smith, M., \& Walden, T. (1998). Developmental trends in emotion understanding among a diverse sample of African-American preschool children. Journal of Applied Developmental Psychology, 19, 177-197.

Sroufe, L. A. (1996). Emotional development: The organization of emotional life in the early years. New York: Cambridge University Press.

Tronick, E. Z. (1989). Emotions and emotional communication in infants. American Psychologist, 44, 112-119.

Walden, T. A., \& Field, T. M. (1982). Discrimination of facial expression by preschool children. Child Development, 53, 1312-1319.

Walker-Andrews, A. S. (1997). Infants' perception of expressive behaviors: Differentiation of multimodal information. Psychological Bulletin, 121, 437-456.

Widen, S. C., \& Russell, J. A. (2003). A closer look at preschoolers' freely produced labels for facial expressions. Developmental Psychology, 39, 114-128.

Widen, S. C., \& Russell, J. A. (2004). The relative power of an emotion's facial expression, label, and behavioral consequence to evoke preschoolers' knowledge of its cause. Cognitive Development, 19, 119-125.

Widen, S. C., \& Russell, J. A. (2008). Children acquire emotion categories gradually. Cognitive Development, 23, 291-312.

Received February 7, 2014

Revision Received February 20, 2014

Accepted February 22, 201 